\title{
EFFECTS OF ORIENTEERING GAME ON DIRECTIONAL RELATIONSHIPS AND INHIBITORY CONTROL IN CHILDREN 7-8 AGED
}

(i) Anis Ben Chikha ${ }^{1+}$
(i) Aymen Hawani ${ }^{2}$
(i) Ghazwa Ben
Maouia $^{3}$

Article History Revised: 21 July 2021

Accepted: 13 August 2021

Published: 8 September 2021

Keywords

Child executive functions

Orienteering game

Inhibitory control

Directional skills.
Received: 15 June 2021

directional skills

\author{
${ }^{\prime}$ Higher Institute of Sport and Physical Education (Ksar Saïd), Tunisia; \\ Research Unit ECOTIDI (UR16ES10), Virtual University, Tunisia. \\ Email:benchikhaanis@yahoo.fr.Tel:0021652282238 \\ ${ }^{2}$ Higher Institute of Sport and Physical Education (Ksar Saïd), Tunisia; \\ Research Unit of the National Sports Observatory (ONS), Physical Activity, \\ Sport \& Health Tunis, Tunisia. \\ Email:hawani.aymen@yahoo.com Tel:0021698239463 \\ ${ }^{3}$ Higher Institute of Sport and Physical Education (Ksar Saïd), Tunisia. \\ Email:ghazrvabm@yahoo.fr.Tel:0021658812151
}

\section{ABSTRACT}

The spatial orientation, ability is very important for the child, for the development of its executive functions such as inhibitory control and directional skills. In fact, the role of play as a locomotive for learning and motivation is very imperative in this age group. Our methodological choice consists of offering a teaching program around the orientation game $(\mathrm{OG})$ that takes place in the school playground. The aim of this study was to examine the effect of $\mathrm{OG}$ on directional skills and inhibitory control. The assessment was respectively conducted by Topological and Directional Relation (RTD) and Stroop Color-Word Test -Victoria version (SCWT). Primary school students $(\mathrm{N}=$ 40; 7.3 years) participated in this study. They were divided into two groups: an experimental group (20 students) and a control group (20 students). The first group followed a 12-week orienteering game (OG) program with 3 sessions of 40 minutes per week and the second a regular physical education program. The results of the experimental group show a clear improvement in most of the study variables.

Contribution/Originality: The paper's primary contribution is highlights the importance of play in the spatial and cognitive development of children, it comes in particular to measure the effect of orientation play on executive functions such as inhibitory control and directional skills.

\section{INTRODUCTION}

There is currently a consensus in the scientific community about the positive effects of physical exercise on cognition (Chang, Labban, Gapin, \& Etnier, 2012). In children, it is important to determine the effects of physical activity on cognitive functioning (Davis et al., 2011; Kamijo et al., 2012). However, using an experimental approach to try to understand these effects on higher cognitive functions, is a very recent advance (Piepmeier \& Etnier, 2015).Thus, more in-depth knowledge of the link between the type of physical activity and cognitive functioning in children can contribute to the development of educational policies in physical education (Blair, Gamson, Thorne, \& Baker, 2005; Borella, Carretti, \& Pelegrina, 2010; Curlik 2nd \& Shors, 2013; Morrison, Ponitz, \& McClelland, 2010).

In this study, we are going to focus on orienteering physical activity, the main challenge of which is to locate oneself, to orient oneself, to organize oneself, and to move as quickly as possible in one's environment. The child must organize the space according to himself (his body, his experience, his way of thinking) and perceive the dimensions, the shape, the limits, the layout of the places, obstacles, and this being able to dispose of them according 
to their needs. This notion of space arouses in children through their cognitive functions their capacity for spatial cognition.

Thus, the ability to orient oneself in the environment and to represent it mentally involves cognitive and spatial skills: attention, inhibition, memory, information processing, planning, mental flexibility, etc. (Osberg, 1997).

Indeed, Péruch and Corazzini (2006) describe spatial cognition as the ability to combine spatial information from different sources and events and to use this knowledge to estimate directions and distances and manage movements.

\section{THEORETICAL BACKGROUND}

\subsection{Orientation and Spatial Cognition}

Knowing how to orient oneself in space, therefore, requires multiple capacities such as being in the environment, ordering different elements of a whole, appreciating the existing relationships between oneself, objects, and others as well as simultaneously integrating different parts of a model.

These capacities are, of course, not innate and it is only during the development that we awaken our capacity to orient our body, to understand and to designate our position in space in relation to different landmarks (immobile, mobile) in order to locate us and move around in the environment (Almond, 2013).

Notably, Péruch and Corazzini (2006) indicate that spatial cognition is "the ability to combine spatial information from different sources and events, in order to use them to estimate directions and distances and manage movements".

Thomas et al. (2005) insist on the fact that the environments mobilized, can be of different nature and describe spatial cognition as "the acquisition, organization, use, and review of knowledge of spatial environments, whether real or abstract, human or artificial". Osberg (1997) defines spatial cognition as a process by which the child perceives stores, recalls, edits, and communicates spatial images.

Spatial cognition is based on internal processes ranging from the precursor concept of "cognitive map" proposed by Tolman (1948) to the mental models of Johnson-Laird (1983) to the current concepts of mental maps or more generally of spatial representations.

Mental maps allow individuals to mentally represent the world around them and thus to know at any time what their position is and which path to take to reach their goals, where the objects that surround them are located, even if they are. They are not visible, how to orient and adapt to changes in an environment, but also how to communicate spatial knowledge to others (Denis, Michon, \& Tom, 2006). The individual is, therefore, able to make inferences, for example concerning the relationships between elements and distances. By creating cognitive maps, the individual performs a dynamic process involving the acquisition, maintenance, internal manipulation, and use of information about the external environment (Golledge, 2004).

Thus, several operations, not completely hierarchical, can be implemented by an individual in the construction of his spatial representation until the implementation of real, cognitive maps (Lockman \& Pick, 1984) through be three operations:

- Reversibility, which consists of being able to travel in both directions.

- Transitivity, that is to say, the subject's capacity, which can go from point A to point B and from point B to point $\mathrm{C}$, to be able to go from point $\mathrm{A}$ to point $\mathrm{C}$ without necessarily passing from point $\mathrm{B}$.

- And the skill of deviation which allows the subject to find different paths to go from point A to point $\mathrm{C}$.

Thanks to these last two skills, an individual will be able to begin to create different routes. However, as long as no link is made between these different journeys, they will remain uncoordinated and there will be no real construction of a cognitive map. It is only when links between these different paths and landmarks will be created that we can truly speak of as a cognitive map. 


\subsection{Inhibitory Control as an Executive Function}

Executive functions refer to the cognitive processes necessary for goal-directed cognition and behavior, which develop across childhood. They can be defined as a set of high-level cognitive processes that govern goal-directed actions and adaptive responses to new and/or complex situations (Miyake et al., 2000). These cognitive control processes are called upon when we have to concentrate on a task, memorize and manipulate information, adapt to new environments or rules, and more generally when habits or automatisms are not sufficient to achieve these goals (Diamond, 2013).

We invoke these cognitive functions: - planning/organizing- Updating working memory - cognitive flexibility - inhibitory control.

We are going to develop only this last executive function that we have found useful to investigate in this study. Inhibitory control is the ability to prevent oneself from producing an automatic response, to stop the production of an ongoing response, and to rule out stimuli irrelevant to the current activity. It is an active mechanism of suppression (Posner \& Rothbart, 1998).

Indeed, this executive function allows the temporary suppression of an automatic, habitual, and dominant response. It prevents the entry of parasitic information and focuses on that which is necessary to act, think, etc. It acts as a filter in working memory. For Harnishfeger (1995) there are two kinds of inhibition: motor (which concerns motor aspects) and conceptual (which has the function of blocking irrelevant information to achieve a goal). It is considered to be a determining factor in cognitive development in childhood (Dempster, 1992).

Studies involving interference tasks have shown that subjects' performance on a visual working memory task decreases when a visual interference task is administered at the same time. This is not the case if it is a spatial interfering task. This is the reverse profile for a spatial working memory task: a spatial stimulus affects a spatial task, not a visual task (Logie \& Marchetti, 1991).

\subsection{Orienteering Game}

While enhancing the role of play as a locomotive for learning and motivation, this methodological choice consists of offering a teaching program around the orientation game. For the development of this program, we have developed situations based on academic skills through the solicitation of executive functions (inhibitory control). The game takes place in the school playground between 4 teams.

It begins with a compass drawn on the ground in the middle of a mini orienteering course with markers in the form of a writing whiteboard. Then, each team must correctly arrange the directions of its different movements using a compass according to the various situations proposed.

Thus, in the present study, our objective was to examine the effect of practicing orienteering on directional skills and inhibitory control. Our hypothesis presupposes that practicing the orienteering game will induce positive changes in children aged 7.3 in their directional skills and inhibitory control.

\section{MATERIAL \& METHODS}

\subsection{Participants}

Forty students had voluntarily participated in this study. They are schooled in both mixed classes of the second year of primary school, each one containing twenty-two students. The classes belong to the same public school and with two different teachers. But we chose two teachers with the same basic training and with the same number of years' experience. To this end, we arrange to work with an experimental group and a control group.

The average age of the participants is 7.3 years. These children attend a public primary school. Their middle parent sociocultural level is defined by the father's job. All these participants are considered normal and welladjusted to schooling. They are all in the classes corresponding to their chronological age and are average students for all school subjects. Their parents were informed and give their agreement signature about the participation of 
their children in the experimental research, and they have the opportunity at any time to withdraw their children from it. The results of this research guarantee anonymity and confidentiality, and the parents may be aware of their children's skills assessment.

\subsection{Data Collection and Analysis}

Our procedure would be of a quasi-experimental type and based on an orienteering game. Our intervention program was spread over 12 weeks, with 3 sessions of 40 minutes per week. The control group followed conventional learning, respecting the same hourly volume as the experimental group.

This program is used to, provides these children with orienteering games that challenge their directional skills and cognitive functions through played learning situations. In this study, we used two tests, namely

- $\quad R T D$ (Topological and Directional Relation Test by Barry (2010):

The segment or Directional Cueing Test examines children's directional skills. The child should then follow a presentation by 11 half-sun segments, each segment being separated by an angle of $18^{\circ}$ initially listed on a sheet "refer" which is laid flat on the table and oriented in portrait, try to minimize the place of a single item on a separate sheet "stimulus". After passing reference to right over, the examiner inverts the reference sheet and stimulus leaves and starts executing it, to refer to the left.

- StroopColor-Word Test-Victoria version (SCWT; Lima, Azoni, and Ciasca (2011); Spreen and Strauss (1998)

This test assesses the ability of inhibitory control and selective visual attention. We used the four color version and 24 stimuli in each of the three parts

- "Color card" (card A): with four-color four colors, using a pseudo-random order.

- "Word card" (card B): with the color names printed in the corresponding colors.

- "Word color card" (C card): with colored names, but printed in different colors, for example, the word "green" printed in blue.

The scores (time /four-colors obtained for each of the cards). Other additional scores were calculated from the previous ones:

- Facilitation: the facilitation process obtained from the presentation of congruent stimuli. The score is obtained by subtracting the time (facilitation-time) and the error scores (facilitation-score): "color card" "word card".

- Interference: which represents the "Stroop" effect due to the incongruous situation of the test? The score is obtained by subtracting the time (interference-time) and the error scores (interference errors): "color word map" - "color map".

In fact, for all tests, the child is interviewed individually in a bright and quiet room of his school in which he is sitting comfortably at a table facing the examiner. The tests and retests were taken at 8 am in the same classroom. It should be noted that after one day of the end of the learning program, the three cognitive tests were taken again for the two groups.

The procedures and methods used in the ASK study conform to the ethical guidelines defined by the World Medical Association's Declaration of Helsinki and its subsequent revisions. The study protocol was approved by The Regional Committee for Medical Research Ethics. We obtained written consent from each child's parents to all testing.

\subsection{Statistical Methods}

We proceeded with a normality test, which showed that the distributions are skewed for all variables/tests. So we used the calculation of the median \pm the interquartile range. Likewise, we used the Mann-Whitney test to compare the two groups and the Wilcoxon test for the comparison between test and retest. 
The size of the sample effect $(r)$ was calculated. Measures of the size of the sample effect are interpreted: $r>$ $0.10,[$ small $] ; \mathrm{r}>0.30,[$ medium $]$; and $\mathrm{r}>0.50$, [large $]$.

For Gaussian distributions, the mean and standard deviation were calculated and then proceeded by the analysis of the ANOVA for repeated measures (e.g., learning effect) at one factor (e.g., experimental group vs. controls). In order to verify the power of the tests performed during the ANOVA, a study of the effect of the sample size "effect size" (d) was established using the software GPOWER software (Bonn FRG, Bonn University, Department of Psychology) (Erdfelder \& Bredenkamp, 1994).

A d <0.2 is described as a "weak" effect, between $0.2-0.6$ "medium", between 1.2 - 2.0 strong and greater than 2.0 as "very strong". (Hopkins, 2002)

We also calculated the delta variation $(\Delta)$ between the test and the pretest with the formula $[\Delta=$ test-retest $]$ and the percentage of the delta variation $(\Delta \%)$ with the formula $[\Delta \%=(($ retest-test $) /$ test $) \times 100]$. The results are considered significant when the probability is less than or equal to $0.05 \%$ ( $\leq \leq 0.05$ ). We used SPSS 20.0 software and Microsoft Excel 2016 for the calculation and statistical analysis.

\section{RESULTS}

\subsection{RTD Test Results}

The results show that initially (before learning) there is no intergroup difference (in both control and experimental group) in all of the variables studied Table 1.

Table-1. U Mann-Whitney test, comparison between the two groups before training (RTD Test).

\begin{tabular}{c|c|c|c|c|c|c|c|c}
\hline $\begin{array}{c}\text { Mann- } \\
\text { Whitney }\end{array}$ & $\begin{array}{c}\text { To } \\
\text { correct R }\end{array}$ & $\begin{array}{c}\text { Toerror } \\
\text { at } \mathbf{1 8} \mathbf{\circ}^{\circ} \mathbf{R}\end{array}$ & $\begin{array}{c}\text { Toerror } \\
>\mathbf{1 8} \mathbf{~}^{\circ}\end{array}$ & TomirrorR & $\begin{array}{c}\text { To } \\
\text { correct } \mathbf{L}\end{array}$ & $\begin{array}{c}\text { To mirror } \\
\text { at } \mathbf{1 8}^{\circ} \mathbf{L}\end{array}$ & $\begin{array}{c}\text { Toerror } \\
>\mathbf{1 8} \mathbf{L}\end{array}$ & $\begin{array}{c}\text { To } \\
\mathbf{m i r r o r} \mathbf{L}\end{array}$ \\
\hline $\mathrm{U}$ & 164.00 & 189.50 & 187.50 & 165.50 & 188.50 & 193.00 & 190.00 & 198.00 \\
\hline $\mathrm{Z}$ & -1.027 & -0.306 & -0.386 & -0.984 & -0.326 & -0.200 & -0.350 & -0.059 \\
\hline $\mathrm{r}$ & $0.162 \sim$ & 0.048 & 0.061 & $0.156 \sim$ & 0.052 & 0.032 & 0.055 & 0.009 \\
\hline
\end{tabular}
0.50 , [large].

In addition, the intragroup study showed a significant difference after learning whether for the experimental or control group Table 2 .

Table-2. Wilcoxon test, comparison between the test (TO) and the retest (T1) for the two groups after learning (RTD Test).

\begin{tabular}{|c|c|c|c|c|c|c|c|c|c|}
\hline $\begin{array}{c}\text { Group / T1 } \\
\text { vs To }\end{array}$ & & $\begin{array}{c}\text { Correct } \\
\text { R }\end{array}$ & $\begin{array}{c}\text { Errorat } \\
18^{\circ} \mathrm{R}\end{array}$ & $\begin{array}{c}\text { Error }> \\
18^{\circ} \mathrm{R}\end{array}$ & MirrorR & $\begin{array}{c}\text { Correct } \\
\mathrm{L}\end{array}$ & Error $18^{\circ} \mathrm{L}$ & Error $>18^{\circ} \mathrm{L}$ & MiroirL \\
\hline \multirow{2}{*}{ Control } & Z & $-2.887 * *$ & $-2.449^{*}$ & $-2.333^{*}$ & -0.816 & $-2.236^{*}$ & -1 & -1.342 & -0.447 \\
\hline & $\mathrm{r}$ & $0.456 \approx$ & $0.387 \approx$ & $0.369 \approx$ & $0.129 \sim$ & $0.354 \approx$ & $0.158 \sim$ & $0.212 \sim$ & 0.071 \\
\hline \multirow{2}{*}{ Experimental } & $Z$ & $-3.964 * *$ & $-3.999 * *$ & $-4.119^{* *}$ & $-3.866^{* *}$ & $-3.943 * *$ & $-3.875^{* *}$ & $-3.557^{* *}$ & $-3.946^{* *}$ \\
\hline & $\mathrm{r}$ & $0.627+$ & $-0.632+$ & $0.651+$ & $0.611+$ & $0.623+$ & $0.613+$ & $0.562+$ & $0.624+$ \\
\hline
\end{tabular}

Legend: (R) right; (L) left; (To) before learning; (T1) after learning; (r) sample size effect; ( ) r>) r $\approx 0.10$, [small]; (>0.30, [medium]; and (+) r>0.50, [broad]; * Significant difference from pre-learning at $\mathrm{p}<0.05$; ** $\mathrm{p}<0.01$.

Thus, the statistical study showed that for the control group, there is a significant difference at $\mathrm{p}<0.05$ for the variables: correct on the right, error at $18^{\circ}$ on the right, error $>18^{\circ}$ on the right, and items correct on the left between the test and the retest. As for the experimental group, there is a significant difference at $\mathrm{p}<0.01$ for all variables. Furthermore, the intergroup comparison after the training showed a significant difference at $p<0.01$ between the two groups Table 3 . 
Table-3. U Mann-Whitney test, comparison between the two groups after training (RTD Test).

\begin{tabular}{c|c|c|c|c|c|c|c}
\hline $\begin{array}{c}\text { Mann- } \\
\text { Whitney }\end{array}$ & $\begin{array}{c}\mathbf{T} 1 \\
\text { correct } \mathbf{R}\end{array}$ & $\begin{array}{c}\mathbf{T} 1 \text { error } \\
\text { at } \mathbf{1 8} \mathbf{\circ}^{\circ} \mathbf{R}\end{array}$ & $\begin{array}{c}\mathbf{T} 1 \text { error } \\
\mathbf{7} \mathbf{1 8} \mathbf{}^{\circ} \mathbf{R}\end{array}$ & $\begin{array}{c}\mathbf{T} 1 \text { mirror } \\
\mathbf{R}\end{array}$ & $\begin{array}{c}\mathbf{T} 1 \\
\text { correct } \mathbf{L}\end{array}$ & $\begin{array}{c}\mathbf{T} 1 \text { error } \\
\text { at } \mathbf{1 8} \mathbf{}^{\circ} \mathbf{L}\end{array}$ & $\begin{array}{c}\mathbf{T} 1 \text { mirror } \\
\mathbf{L}\end{array}$ \\
\hline $\mathrm{U}$ & 1.00 & 48.00 & 78.00 & 32.50 & 5.00 & 49.00 & 60.00 \\
\hline $\mathrm{Z}$ & $-5.466 \# \#$ & $-4.271 \# \#$ & $-3.653 \# \#$ & $-4.792 \# \#$ & $-5.334 \# \#$ & $-4.204 \# \#$ & $-3.940 \# \#$ \\
\hline $\mathrm{R}$ & $0.864+$ & $0.675+$ & $0.578+$ & $0.758+$ & $0.843+$ & $0.665+$ & $0.623+$ \\
\hline
\end{tabular}

Legend: (R) right; (L) left; (T1) after learning; $(\mathrm{r})$ sample size effect; $(\sim) \mathrm{r}>) \mathrm{r} \approx 0.10$, [small]; $(>0.30$, [medium]; and $(+) \mathrm{r}>0.50$, [broad]; \# Significant difference from the control group at $\mathrm{p}<0.05$; \#\# $\mathrm{p}<0.01$.

Likewise, the U Mann-Whitney test shows a significant difference at $\mathrm{p}<0.01$ with regard to the delta variation for the two groups Table 4 .

Table-4. U Mann-Whitney test, comparison of the delta variation between the two groups (RTD Test).

\begin{tabular}{c|c|c|c|c|c|c|c|c}
\hline $\mathbf{R}$ & $\begin{array}{c}\mathbf{D V} \\
\text { correct } \mathbf{R}\end{array}$ & $\begin{array}{c}\mathbf{D V} \text { error } \\
\mathbf{a t 1 8}^{\circ} \mathbf{R}\end{array}$ & $\begin{array}{c}\mathbf{D V} \text { error } \\
\mathbf{>} \mathbf{1 8}^{\circ} \mathbf{R}\end{array}$ & $\begin{array}{c}\mathbf{D V} \text { mirror } \\
\mathbf{R}\end{array}$ & $\begin{array}{c}\mathbf{D V} \\
\text { correct at } \mathbf{L}\end{array}$ & $\begin{array}{c}\mathbf{D V} \text { error } \\
\text { at } \mathbf{1 8} \mathbf{~}\end{array}$ & $\begin{array}{c}\mathbf{D V} \text { error } \\
\mathbf{>} \mathbf{1 8}^{\circ} \mathbf{L}\end{array}$ & $\begin{array}{c}\mathbf{D V} \\
\text { mirror } \mathbf{L}\end{array}$ \\
\hline $\mathrm{U}$ & 1.50 & 17.00 & 45.00 & 45.00 & 4.50 & 36.50 & 83.00 & 49.00 \\
\hline $\mathrm{Z}$ & $-5.43 \# \#$ & $-5.08 \# \#$ & $-4.48 \# \#$ & $-4.62 \# \#$ & $-5.43 \# \#$ & $-4.63 \# \#$ & $-3.65 \# \#$ & $-4.30 \# \#$ \\
\hline $\mathrm{r}$ & $0.859+$ & $0.803+$ & $0.708+$ & $0.730+$ & $0.859+$ & $0.732+$ & $0.577+$ & $0.680+$ \\
\hline
\end{tabular}

Legend: (R) right; (L) left; (DV) delta variation; (r) sample size effect; $(\sim) \mathrm{r}>) \mathrm{r} \approx 0.10$, [small]; $(>0.30$, [medium]; and $(+) \mathrm{r}>0.50$, [broad $]$; \# Significant difference from the control group at $\mathrm{p}<0.05$; \#\# $\mathrm{p}<0.01$

Table 5 summarizes the results of the RTD test for the different variables studied.

Table-5. Medians and interquartile ranges of study parameters before and after training for the two groups (RTD Test).

\begin{tabular}{|c|c|c|c|c|c|c|c|}
\hline \multirow{2}{*}{ Parameters } & \multicolumn{3}{|c|}{ Control Group $(\mathrm{N}=20)$} & & \multicolumn{3}{|c|}{ Experimental Group $(\mathrm{N}=20)$} \\
\hline & Before & After & $\Delta(\Delta \%)$ & & Before & After & $\Delta(\Delta \%)$ \\
\hline Number of correct answers R & $5 \pm 1$ & $5 \pm 1 * *$ & $0.50(11.33 \%)$ & & $5 \pm 2$ & $9 \pm 2 * * \# \#$ & $4.15(89.41 \%) \# \#$ \\
\hline Number of errors at $18^{\circ} \mathrm{R}$ & $3 \pm 2$ & $3 \pm 2 *$ & $-0.30(-10 \%)$ & $3 \pm 1$ & $1 \pm 1$ & **\#\# & $-01.80(-59.16 \%) \# \#$ \\
\hline Number of errors $>18^{\circ} \mathrm{R}$ & $1 \pm 1$ & $1 \pm 0^{*}$ & $-0.35(-20 \%)$ & & $1 \pm 1$ & $0 \pm 1 * * \# \#$ & $-01.10(-83.33 \%) \# \#$ \\
\hline Number of mirrorsR & $2 \pm 1$ & $2 \pm 1$ & $0.10(00 \%)$ & & $1 \pm 1$ & $0 \pm 1 * * \# \#$ & $-01.25(-79.16 \%) \# \#$ \\
\hline Number of correct answers L & $5 \pm 1$ & $5 \pm 2^{*}$ & $0.25(05.33 \%)$ & & $5 \pm 2$ & $9 \pm 2 * * \# \#$ & 03.80 (86.91\%)\#\# \\
\hline Number of errors at $18^{\circ} \mathrm{L}$ & $3 \pm 2$ & $3 \pm 2$ & $-0.10(-04.16 \%)$ & & $3 \pm 2$ & $1 \pm 1 * \# \# \#$ & $-01.80(-57.83 \%) \# \#$ \\
\hline Number of errors $>18^{\circ} \mathrm{L}$ & $1 \pm 1$ & $1 \pm 1$ & $-0.15(-10 \%)$ & & $1 \pm 1$ & $0 \pm 1 * * \# \#$ & $-00.80(-62.50 \%) \# \#$ \\
\hline Number of mirrorsL & $2 \pm 1$ & $2 \pm 2$ & $0.05(01.66 \%)$ & & $2 \pm 1$ & $0 \pm 1 * * \# \#$ & $-01.35(-73.33 \%) \# \#$ \\
\hline
\end{tabular}

\subsection{Resultsof SCWTTest}

The results of the SCWT test show that there is no significant difference between the two groups before training Table 6.

Table-6. Test of U Mann-Whitney, comparaisonbetween the twogroups beforetraining (SCWT Test).

\begin{tabular}{c|c|c|c|c|c|c|c|c|c|c}
\hline $\begin{array}{c}\text { Mann- } \\
\text { Whitney }\end{array}$ & $\begin{array}{c}\text { EC } \\
\text { Error } \\
\text { To }\end{array}$ & $\begin{array}{c}\text { CC } \\
\text { Time } \\
\text { To }\end{array}$ & $\begin{array}{c}\text { NC } \\
\text { Error } \\
\text { To }\end{array}$ & $\begin{array}{c}\text { NC } \\
\text { Time } \\
\text { To }\end{array}$ & $\begin{array}{c}\text { IC } \\
\text { ErrorTo }\end{array}$ & $\begin{array}{c}\text { IC } \\
\text { Time } \\
\text { To }\end{array}$ & $\begin{array}{c}\text { Facilitat } \\
\text { ionError } \\
\text { To }\end{array}$ & $\begin{array}{c}\text { Facilitatio } \\
\text { nime } \\
\text { To }\end{array}$ & $\begin{array}{c}\text { Interference } \\
\text { Error } \\
\text { To }\end{array}$ & $\begin{array}{c}\text { Interference } \\
\text { Time } \\
\text { To }\end{array}$ \\
\hline $\mathrm{U}$ & 198.00 & 189.50 & 183.00 & 199.50 & 197.50 & 200.00 & 190.00 & 189.50 & 187.50 & 185.00 \\
\hline $\mathrm{Z}$ & -0.078 & -0.284 & -0.546 & -0.014 & -0.074 & 0.000 & -0.335 & -0.284 & -0.364 & -0.406 \\
\hline $\mathrm{R}$ & $0.012 \sim$ & $0.045 \sim$ & $0.086 \sim$ & $0.002 \sim$ & $0.012 \sim$ & $0.000 \sim$ & $0.053 \sim$ & $0.045 \sim$ & $0.057 \sim$ & $0.064 \sim$ \\
\hline
\end{tabular}

Legend: (CC) Congruent condition; (NC) Neutral condition; (IC) Incongruent condition; (r) sample size effect; ( ) r >) r $\square 0.10$, [small]; (>0.30, [medium]; and $(+) \mathrm{r}>0.50$, [large]

For the intragroup comparison, the results show a significant difference at $\mathrm{p}<0.05$ for the control group and the experimental group Table 7 . 
Table-7. Wilcoxon test, comparison between the test (To) and the retest (T1) for the two groups after training (SCWT Test).

\begin{tabular}{|c|c|c|c|c|c|c|c|c|c|c|c|}
\hline $\begin{array}{l}\text { Group / } \\
\text { T1 vs To }\end{array}$ & & $\begin{array}{l}\text { CC } \\
\text { Error }\end{array}$ & $\begin{array}{l}\text { CC } \\
\text { Time }\end{array}$ & $\begin{array}{l}\mathrm{NC} \\
\text { Error }\end{array}$ & $\begin{array}{l}\text { NC } \\
\text { Time }\end{array}$ & $\begin{array}{l}\text { IC } \\
\text { Error }\end{array}$ & $\begin{array}{l}\text { IC } \\
\text { Time }\end{array}$ & $\begin{array}{l}\text { Facilitation } \\
\text { Error }\end{array}$ & $\begin{array}{l}\text { Facilitation } \\
\text { Time }\end{array}$ & $\begin{array}{l}\text { Interference } \\
\text { Error }\end{array}$ & $\begin{array}{l}\text { Interference } \\
\text { Time }\end{array}$ \\
\hline \multirow{2}{*}{ control } & $\mathrm{Z}$ & -1 & $-3.046^{* *}$ & -0.707 & $-3.499^{* *}$ & -0.782 & $-2.922^{*} *$ & 0.000 & -0.36 & -0.58 & -0.112 \\
\hline & $\mathrm{R}$ & $0.158 \sim$ & $0.482 \approx$ & $0.112 \sim$ & $0.553+$ & $0.124 \sim$ & $0.462 \approx$ & 0.000 & 0.057 & 0.092 & 0.018 \\
\hline \multirow{2}{*}{ Experimental } & $\mathrm{Z}$ & -1.633 & $-3.555^{*}$ & -1.667 & $-3.926^{* *}$ & $-2.456^{*}$ & $-3.923 * *$ & -0.302 & -2.121 & $-1.551^{*}$ & -0.654 \\
\hline & $\mathrm{R}$ & $0.258 \sim$ & $0.562+$ & $0.264 \sim$ & $0.621+$ & $0.388 \approx$ & $0.620+$ & $0.048 \sim$ & $0.335 \approx$ & $0.245 \sim$ & $0.103 \sim$ \\
\hline
\end{tabular}

Legend: (CC) Congruent condition; (NC) Neutral condition; (IC) Incongruent condition; (T0) before learning; (T1) after learning; (r) sample size effect; ; $\sim$ r $>$ ) $\mathrm{r} \square 0.10$, [small]; (> 0.30, [medium]; and (+) r> 0.50, [broad]; * Significant difference from pre-learning at $\mathrm{p}<0.05 ; * * \mathrm{p}<0.01$.

Table-8. U Mann-Whitney test, comparison between the two groups after training (SCWT Test).

\begin{tabular}{l|l|l|l|l|l|l|l|l|l|l}
\hline Mann-Whitney & $\begin{array}{l}\text { FA } \\
\text { Error } \\
\text { T1 }\end{array}$ & $\begin{array}{l}\text { FA } \\
\text { Time } \\
\text { T1 }\end{array}$ & $\begin{array}{l}\text { FB } \\
\text { Error } \\
\text { T1 }\end{array}$ & $\begin{array}{l}\text { FB } \\
\text { Time } \\
\text { T1 }\end{array}$ & $\begin{array}{l}\text { FC } \\
\text { Error T1 }\end{array}$ & $\begin{array}{l}\text { FC } \\
\text { Time T1 }\end{array}$ & $\begin{array}{l}\text { Facilitation } \\
\text { Error } \\
\text { T1 }\end{array}$ & $\begin{array}{l}\text { Facilitation } \\
\text { Time } \\
\text { T1 }\end{array}$ & $\begin{array}{l}\text { Interference } \\
\text { Error } \\
\text { T1 }\end{array}$ & $\begin{array}{l}\text { Interference } \\
\text { Time } \\
\text { T1 }\end{array}$ \\
\hline $\mathrm{U}$ & 170.00 & 173.00 & 168.00 & 141.00 & 187.00 & 131.50 & 189.00 & 190.00 & 192.00 & 177.00 \\
\hline $\mathrm{Z}$ & -1.416 & -0.732 & -1.114 & -1.607 & -0.403 & -1.858 & -0.362 & -0.272 & -0.256 & -0.623 \\
\hline $\mathrm{R}$ & $0.224 \sim$ & $0.116 \sim$ & $0.176 \sim$ & $0.254 \sim$ & 0.064 & $0.294 \sim$ & 0.057 & 0.043 & 0.040 & 0.099 \\
\hline
\end{tabular}

Legend: (FA) color card; (FB) word card; (FC) color word card; (T1) after learning; (r) sample size effect; $(\sim) \mathrm{r}>$ ) $\mathrm{r} \square 0.10$,

$[$ small $] ;(>0.30$, [medium $]$; and $(+) \mathrm{r}>0.50$, [large $]$.

\begin{tabular}{c|c|c|c|c|c|c|c|c|c|c}
\hline \multicolumn{2}{|c|}{ Table-9. U Mann-Whitney test, comparison of the delta variation between the two groups (SCWT Test). } \\
\hline \multirow{2}{*}{ Mann-Whitney } & $\begin{array}{c}\text { DV CC } \\
\text { Error }\end{array}$ & $\begin{array}{c}\text { DV CC } \\
\text { Time }\end{array}$ & $\begin{array}{c}\text { DV } \\
\text { NCError }\end{array}$ & $\begin{array}{c}\text { DV } \\
\text { NC } \\
\text { Time }\end{array}$ & $\begin{array}{c}\text { DV } \\
\text { IC } \\
\text { Error }\end{array}$ & $\begin{array}{c}\text { DV } \\
\text { IC } \\
\text { Time }\end{array}$ & $\begin{array}{c}\text { DV } \\
\text { Facilitation } \\
\text { Error }\end{array}$ & $\begin{array}{c}\text { DV Facilitation } \\
\text { Time }\end{array}$ & $\begin{array}{c}\text { DV Interference } \\
\text { Error }\end{array}$ & $\begin{array}{c}\text { DV Interference } \\
\text { Time }\end{array}$ \\
\hline U & 190.00 & 156.50 & 182.50 & 117.00 & 183.50 & 100.00 & 181.50 & 187.50 & 171.00 & 166.50 \\
\hline $\mathrm{Z}$ & -0.409 & -1.186 & -0.560 & $-2.260 \#$ & -0.474 & $-2.720 \# \#$ & -0.561 & -0.339 & -0.878 & -0.908 \\
\hline $\mathrm{R}$ & 0.065 & $0.187 \sim$ & 0.089 & $0.357 \approx$ & 0.075 & $0.430 \approx$ & 0.089 & 0.054 & $0.139 \sim$ & $0.144 \sim$ \\
\hline
\end{tabular}

Legend: (CC) Congruent condition; (NC) Neutral condition; (FC) Incongruent condition; (DV) delta variation; (r) sample size effect; ( ) r> ) r $\square 0.10$, [small]; (> 0.30, [medium]; and (+) r>0.50, [broad]; \# Significant difference from the control group at $\mathrm{p}<0.05$; \#\# $\mathrm{p}<0.01$. 
In addition, the intergroup comparison after training shows no significant difference, Table 8.

On the other hand, there is a significant difference at $\mathrm{p}<0.05$ between the delta variations of each group Table 9.

The following table summarizes the results of the SCWTTest Table 10.

Table-10. Medians and interquartile ranges of study parameters before and after training for the two groups (SCWT Test).

\begin{tabular}{|c|c|c|c|c|c|c|}
\hline & \multicolumn{3}{|c|}{ Group control $\left(n_{1}=20\right)$} & \multicolumn{3}{|c|}{ Groupexperimental $\left(\mathrm{n}_{2}=20\right)$} \\
\hline & Before & After & $\Delta(\Delta \%)$ & Before & After & $\Delta(\Delta \%)$ \\
\hline CCError & $\mathrm{O} \pm \mathrm{O}$ & $\mathrm{O} \pm \mathrm{O}$ & $-0.10(-33.33 \%)$ & $\mathrm{O} \pm \mathrm{O}$ & $\mathrm{O} \pm \mathrm{O}$ & $-0.20(-80.00 \%)$ \\
\hline NCError & $\mathrm{O} \pm 1$ & $\mathrm{O} \pm 1$ & $-0.10(-20.00 \%)$ & $\mathrm{O} \pm 1$ & $\mathrm{O} \pm \mathrm{O}$ & -25 oO $(-55.56 \%)$ \\
\hline NC Time & $24 \pm 7$ & $21 \pm 5 * *$ & $-3.40(-13.71 \%)$ & $23.5 \pm 6$ & $20 \pm 3 * *$ & $-5.05(-20.40 \%) \#$ \\
\hline Facilitation Error & $\mathrm{O} \pm \mathrm{O}$ & $\mathrm{O} \pm 1$ & $0.00(0.00 \%)$ & $\mathrm{O} \pm 1$ & $\mathrm{O} \pm \mathrm{O}$ & $0.05(-25.00 \%)$ \\
\hline Facilitation Time & $-3.5 \pm 20$ & $-2 \pm 16$ & $0.40(-27.59 \%)$ & $-1.5 \pm 10$ & $\mathrm{O} \pm 3$ & $0.25(-16.13 \%)$ \\
\hline InterferenceError & $\mathrm{O} \pm 2$ & $\mathrm{O} \pm 1$ & $-0.10(-16.67 \%)$ & $\mathrm{O} \pm 2$ & $\mathrm{O} \pm 1 *$ & $-0.30(-42.86 \%)$ \\
\hline InterferenceTime & $17.5 \pm 18$ & $13.5 \pm 13$ & $-0.25(-2.03 \%)$ & $11 \pm 14$ & $9 \pm 16$ & $-2.65(-20.46 \%)$ \\
\hline
\end{tabular}

at $\mathrm{p}<0.05$; ** $\mathrm{p}<0.01$; \# Significant difference from the control group at $\mathrm{p}<0.05$; \#\# $\mathrm{p}<0.01$.

\section{DISCUSSION}

We note that the originality of our choice is due to the fact that OG as such differs from the activities proposed in the works focused on $t$ acute effects of physical exercise and its impact on higher cognitive functions (Chu, Alderman, Wei, \& Chang, 2015; Davranche, Brisswalter, \& Radel, 2015; Howie, Schatz, \& Pate, 2015; Pontifex, Parks, Henning, \& Kamijo, 2015).

The main findings from this study were:

Firstly, the benefits of practicing orienteering on directional skills. Analysis of the RTD Test results confirms them for all variables at $\mathrm{p}<0.05$. Our results are consistent with the propositions of which mention that movement is at the source of spatial knowledge. In the same sense, they described a space of action, sensorimotor, followed by a space of representation which becomes more and more complex as a result of experience and neuropsychological maturity. Thus, the solicitation of perceptual and motor functions contributes to the construction of space in children (Feuillerat, 2005). Otherwise, the child acquires during his development, first, the ability to orient his body, then to understand and designate his position in space, and finally to locate himself in the environment until developing a real representation of, space.

We also found that the intergroup comparison showed a significant difference aft, her learning at $\mathrm{p}<0.01$ for all the variables studied in favor of the experimental group (number of correct responses to R: $\Delta \% \operatorname{control}=11.33 \%$ vs. $\Delta \%$ experimental $=89.41 \%)$. This allowed us to conclude that the pupils who participated in our learning program (OG) enjoyed better improvement than those who followed the regular learning program.

On the other hand, the results of the present study also confirm that the practice of OG has a positive effect on the inhibitory capacity in children: indeed, the analyses have shown a significant difference at $\mathrm{p}<0.01$ for variables (Congruent condition, Neutral condition, Incongruent condition) relating to the two groups. However, the comparison of intragroup facilitation and interference scores, showed that there was no significant difference except for the variable interference error at $\mathrm{p}<0.05$ in favor of the experimental group.

This result confirms the improvement of the inhibitory control following the practice of OG against the control group which was not mentioned as a significant gain in the Stroop effect (interference score).

Moreover, the analysis of the delta percentage showed that the experimental group benefited from a more considerable decrease in terms of error or / and time during the facilitation and interference scores (e.g., facilitation $\Delta \%$ control error $=00.00 \%$ vs $\Delta \%$ experimental $=-25.00 \%$, facilitation time $\Delta \%$ control $=-27.59 \%$ vs $\Delta \%$ experimental $=-16.13 \%$, interference error $\Delta \%$ control $=-16.67 \%$ vs $\Delta \%$ experimental $=-42.86 \%$, time interference 
$\Delta \%$ control $=-02.03 \%$ vs $\Delta \%$ experimental $=-20.46 \%)$. This led us to conclude that the control group certainly benefited from a gain in error and time measurements in all the variables of the SCWT Test (except for the error facilitation variable) following their participation in regular learning. However, this gain was less significant compared to that of the experimental group.

This is furthermore supported by intervention studies, where participation in enhanced physical activity in regard to cognitive- and motor challenges, have been shown to have better effects on executive functions compared to physical activity without this enhancement (Pesce et al., 2016). Certainly, all these studies agree on the benefits of the practice of physical activity on executive functions and subsequently on the child's inhibitory control. However, these conclusions must be interpreted with a certain reserve since the parameters of the intervention (nature, duration, frequency, and intensity) were all different.

\section{CONCLUSION}

This study is one of the rare works that have been interested in studying the effect of the practice of specific activity on the cognitive functioning and directional skills of the child, but additional studies are essential to put all the wealth of PA at the service of cognitive and motor needs of children at school.

Funding: This study received no specific financial support.

Competing Interests: The authors declare that they have no competing interests.

Acknowledgement: The authors express their sincerest gratitude to the editors and blind reviewers who have shared their expertise and guidance for the opportunity laid through this paper.

\section{REFERENCES}

Almond, L. (2013). Physical literacy and fundamental movement skills: An introductory critique. ICSSPE Bull J Sport Sci Phys Educ, 65, 80-88.

Barry, V. (2010). Test of topological and directional relations. RTD Lacert Recalibration 2010. Retrieved from: http://www.geppe.free.fr/article.php3?id_article=265. [Accessed $26 / 11 / 2010$ ].

Blair, C., Gamson, D., Thorne, S., \& Baker, D. (2005). Rising mean IQ: Cognitive demand of mathematics education for young children, population exposure to formal schooling, and the neurobiology of the prefrontal cortex. Intelligence, 33(1), 93106. Available at: https://doi.org/10.1016/j.intell.2004.07.008.

Borella, E., Carretti, B., \& Pelegrina, S. (2010). The specific role of inhibition in reading comprehension in good and poor comprehenders. Journal of Learning Disabilities, 43(6), 541-552. Available at: https://doi.org/10.1177/0022219410371676.

Chang, Y.-K., Labban, J. D., Gapin, J. I., \& Etnier, J. L. (2012). The effects of acute exercise on cognitive performance: A metaanalysis. Brain Research, 1453, 87-101. Available at: https://doi.org/10.1016/j.brainres.2012.02.068.

Chu, C.-H., Alderman, B. L., Wei, G.-X., \& Chang, Y.-K. (2015). Effects of acute aerobic exercise on motor response inhibition: an ERP study using the stop-signal task. Journal of Sport and Health Science, 4(1), 73-81. Available at: https://doi.org/10.1016/j.jshs.2014.12.002.

Curlik 2nd, D., \& Shors, T. (2013). Training your brain: Do mental and physical (MAP) training enhance cognition through the process of neurogenesis in the hippocampus? Neuropharmacology, 64, 506-514. Available at: https://doi.org/10.1016/j.neuropharm.2012.07.027.

Davis, C. L., Tomporowski, P. D., McDowell, J. E., Austin, B. P., Miller, P. H., Yanasak, N. E., . . Naglieri, J. A. (201 1). Exercise improves executive function and achievement and alters brain activation in overweight children: A randomized, controlled trial. Health psychology, 30(1), 91-98. Available at: https://doi.org/10.1037/a0021766.

Davranche, K., Brisswalter, J., \& Radel, R. (2015). Where are the limits of the effects of exercise intensity on cognitive control? Journal of Sport and Health Science, 4(1), 56-63. Available at: https://doi.org/10.1016/j.jshs.2014.08.004. 
Dempster, F. N. (1992). Using tests to promote learning: A neglected classroom resource. Journal of Research \& Development in Education, 25(4), 213-217.

Denis, M., Michon, P.-E., \& Tom, A. (2006). Assisting pedestrian way-finding in urban settings : Why references to landmarks are crucial in direction-giving ", in G. L. Allen (éd.), Applied Spatial Cognition: From Research to Cognitive Technology (pp. 25-51). Erlbaum Mahwah (N.J.).

Diamond, A. (2013). Executive functions. Annual Review of Psychology, 11(1), 1-29.

Erdfelder, E., \& Bredenkamp, J. (1994). Hypothesenprüfung [Evaluation of hypotheses]. In T. Herrmann \& W. H. Tack (Eds.),Methodologische Grundlagen der Psychologie (pp. 604-648). Göttingen, Germany: Hogrefe.

Feuillerat, B. (2005). Interest in enriching the psychomotor assessment by tests resulting from professional and multidisciplinary experience. Psychomotricity Interviews, French Scientific Expansion, 24(1), 188-194.

Golledge, R. G. (2004). Using our human resources". In Presidential musings from the meridian: Reflections on the nature of geography by past presidents of the Association of American Geographers, Edited by: Nellis, M. D., Monk, J. and Cutter, S. L (pp. 105-109). Morgantown: West Virginia University Press.

Harnishfeger, K. K. (1995). The development of cognitive inhibition: Theories, definitions, and research evidence. In F. N. Dempster \& C. J. Brainerd (Eds.), Interference and inhibition in cognition (pp. 175-204): Academic Press.

Hopkins, W. G. (2002). A scale of magnitudes for effect statistics. A new view of statistics. Retrieved from: www.sportsci.org/resource/stats/effectmag.html. [Accessed 13 June 2002].

Howie, E. K., Schatz, J., \& Pate, R. R. (2015). Acute effects of classroom exercise breaks on executive function and math performance: A dose-response study. Research Quarterly for Exercise and Sport, 86(3), 217-224. Available at: https://doi.org/10.1080/02701367.2015.1039892.

Johnson-Laird, P. N. (1983). Mental models. Towards a cognitive science of language, inference and consciousness. Cambridge, UK: Cambridge University.

Kamijo, K., Khan, N. A., Pontifex, M. B., Scudder, M. R., Drollette, E. S., Raine, L. B., . . Hillman, C. H. (2012). The relation of adiposity to cognitive control and scholastic achievement in preadolescent children. Obesity, 20(12), 2406-2411. Available at: https://doi.org/10.1038/oby.2012.112.

Lima, R. F. D., Azoni, C. A. S., \& Ciasca, S. M. (2011). Attentional performance and executive functions in children with learning difficulties. Psychology: Reflection and Criticism, 24, 685-691.

Lockman, J. J., \& Pick, H. L., Jr. (1984). Problems of scale in spatial development. In "Origins of cognitive skills". C. Sophian (Ed.). Hillsdale, NJ.: Lawrence Erlbaum Associates.

Logie, R. H., \& Marchetti, C. (1991). Visuo-spatial working memory: Visual, spatial or central executive? In R. H. Logie \& M. Denis (Eds.), Advances in psychology, 80. Mental images in human cognition (pp. 105-115): North-Holland.

Miyake, A., Friedman, N. P., Emerson, M. J., Witzki, A. H., Howerter, A., \& Wager, T. D. (2000). The unity and diversity of executive functions and their contributions to complex "frontal lobe" tasks: A latent variable analysis. Cognitive Psychology, 41(1), 49-100. Available at: https://doi.org/10.1006/cogp.1999.0734.

Morrison, F., Ponitz, C., \& McClelland, M. (2010). Child development at the intersection of emotion and cognition. US: Washington, DC: American Psychological Association.

Osberg, K. M. (1997). The effect of having grade seven students construct virtual environments on their comprehension of science. Paper presented at the Annual Meeting of the American Educational Research Association, Chicago, II.

Péruch, P., \& Corazzini, L. (2006). Move and navigate in space. In P. Fuchs, G. Moreau, A. Berthoz \& J.-L. Vercher (Eds.), The virtual reality treatise (Vol. 1, pp. 189-204). Paris: The Presses des Mines de Paris.

Pesce, C., Masci, I., Marchetti, R., Vazou, S., Sääkslahti, A., \& Tomporowski, P. D. (2016). Deliberate play and preparation jointly benefit motor and cognitive development: Mediated and moderated effects. Frontiers in Psychology, 7, 349. Available at: https://doi.org/10.3389/fpsyg.2016.00349. 
Piepmeier, A. T., \& Etnier, J. L. (2015). Brain-derived neurotrophic factor (BDNF) as a potential mechanism of the effects of acute exercise on cognitive performance. Journal of Sport and Health Science, 4(1), 14-23. Available at: https://doi.org/10.1016/j.jshs.2014.11.004.

Pontifex, M. B., Parks, A. C., Henning, D. A., \& Kamijo, K. (2015). Single bouts of exercise selectively sustain attentional processes. Psychophysiology, 52(5), 618-625. Available at: https://doi.org/10.1111/psyp.12395.

Posner, M. I., \& Rothbart, M. K. (1998). Attention, self-regulation, and consciousness. Philosophical Transactions of the Royal Society of London, 353(1377), 1915-1927.

Spreen, O., \& Strauss, E. (1998). A compendium of neuropsychological tests- administration, norms and commentary. New York: Oxford University Press.

Thomas, B., John, B., Christian, F., Universität, B., Wolfram, B., \& Markus, K. (2005). Transregional collaborative research center SFB/TR 8 spatial cognition: Reasoning: Universität Freiburg.

Tolman, E. (1948). Cognitive maps in man and animals. Psychological Review, 55(4), 189-208. Available at: https://doi.org/10.1037/ho061626.

Views and opinions expressed in this article are the views and opinions of the author(s), Journal of Sports Research shall not be responsible or answerable for any loss, damage or liability etc. caused in relation to/arising out of the use of the content. 